\title{
A MUDANÇA NO CENÁRIO RELIGIOSO BRASILEIRO: O REARRANJO ESPACIAL DO MOVIMENTO PENTECOSTAL
}

\section{CHANGE IN BRAZILIAN RELIGIOUS CONFIGURATION: THE SPATIAL REARRANGE OF PENTECOSTAL MOVEMENT}

Ricardo Henrique Palhares ${ }^{1}$ https://orcid.org/0000-0002-9786-3683

\footnotetext{
${ }^{1}$ Doutor em Geografia pela PUC Minas. Professor do Departamento de Geociências e PPGEO - Universidade Estadual de Montes Claros - Unimontes. E-mail: ricardo.palhares@unimontes.br
}

\begin{abstract}
Resumo
A mudança no cenário religioso ao longo das décadas no Brasil sugeriu uma investigação exploratória no estado de Minas Gerais nos períodos 1991, 2000 e 2010. O crescimento dos protestantes pentecostais permitiu compreender a evolução e o quadro atual da distribuição espacial do respectivo grupo religioso. Foram utilizadas variáveis e indicadores relacionados à religião e migração e o agrupamento dos dados permitiu visualizar através de produtos cartográficos ganhos populacionais nas diferentes mesorregiões mineiras.
\end{abstract}

Palavras-chave: Religião; Difusão Pentecostal; Minas Gerais.

\begin{abstract}
The change in the religious scenario over the decades in Brazil suggested an exploratory investigation in the state of Minas Gerais in the periods 1991, 2000 and 2010. The growth of Pentecostal Protestants allowed us to understand the evolution and the spatial distribution of the respective religious group. Variables and indicators related to religion and migration were used, and the grouping of data allowed visualizing population gains in different state regions through cartographic products.
\end{abstract}

Keywords: Religion; Pentecostal Diffusion; Minas Gerais. 


\section{INTRODUÇÃO}

O crescimento acentuado de grupos oriundos do Protestantismo foi observado no Brasil através dos Censos de 1991 e 2000, no qual se verificou o enfraquecimento do Catolicismo. O Censo Demográfico de 2010 não apenas confirmou as tendências anteriores, como demonstrou o contínuo crescimento dos pentecostais em detrimento dos católicos (IBGE, 2010).

Portanto, diante das recentes mudanças do cenário religioso brasileiro, uma análise desta evolução permitiu reavaliar a nova configuração religiosa apresentada. Análises comparativas sobre o deslocamento ou mesmo estabilização dos grupos evangélicos pentecostais se fez necessária, visto a redução no volume de migrantes do qüinquiênio 2005/2010 em relação ao anterior de 1995/2000 (IBGE, 2010).

Além disso, a construção e posteriormente análise do deslocamento e distribuição espacial do referido grupo religioso é um importante instrumento para estudos que visem beneficiar órgãos de planejamento e gestão do espaço, estudos regionais, mostrando muito da realidade religiosa em Minas Gerais, tanto para o Governo quanto para esta parcela de população religiosa migrante.

Sendo assim, o estudo permitiu segundo o enfoque regional compreender a evolução e o quadro atual da distribuição espacial do movimento pentecostal, segundo deslocamentos migratórios em Minas Gerais, a partir dos dados do Censo Demográfico de 2010.

\section{A dinâmica espacial e religiosa no Brasil}

O primeiro aspecto a se considerar sobre a religião no Brasil é que esta é uma das variáveis sociodemográficas que mais mudaram no país. Sobre este assunto, Neri (2008) afirma que ao lado da religião, outros fatores que se destacaram foram a incorporação do gênero feminino ao mercado de trabalho e a crescente escolarização da população. Certamente, são questões que caminham juntas, cujo esclarecimento demanda maiores aprofundamentos sobre a relação entre a variável religião e os outros fenômenos decorrentes da urbanização.

Costa (1979) comenta que o processo de mudança religiosa parece está fortemente interligado com processos de migração populacional, o que eventualmente pode ser associado a questões como mudança de identidade ou perda do sentimento de pertencimento a grupos sociais específicos. 
Esta mudança de identidade cultural da população é confirmada por Jacob (2003). O mesmo explica que as populações migrantes ao se desligarem dos vínculos de dependência mútua dos locais de origem acabam fixando residência em regiões de expansão da fronteira rural e nas periferias das cidades, notadamente nas regiões metropolitanas. Estas novas áreas de atração acabam exercendo também um papel importante na distribuição espacial religiosa da população, não só no Brasil, mas principalmente em Minas Gerais, gerando de certo modo, uma mudança no perfil religioso da população.

A análise do fenômeno religioso e sua dinâmica no espaço se inserem dentro da abordagem da Geografia da Religião, temática da Geografia Cultural que tem como objetivo chamar a atenção para a análise do espaço das religiões, sobretudo no Brasil, onde as mesmas desempenham um importante papel na formação histórico-cultural.

Dentro desta abordagem merecem destaque os trabalhos de Rosendahl (1995, 2005); Haesbaert (1997); Almeida (2001, 2002); Gil Filho (2002, 2007); Antoniazzi (2004); Claval (1992) e Ratts (2003). Em se tratando da Geografia da Religião, Rosendahl é uma das principais expoentes no Brasil, discutindo conceitos como o sagrado e o profano em uma perspectiva geográfica.

O estudo do fenômeno religioso e sua relação com o território remontam ao início do século XX e vem sendo objeto de interesse por parte dos geógrafos e especialistas em estudos da população, principalmente a partir da década de 1960, onde há uma valorização da relação mútua entre religião e paisagem, a valorização simbólica dos lugares e sua representação no espaço. Tal análise apresenta como influência as perspectivas possibilistas da Escola Vidaliana de Geografia, como também da Escola de Geografia Cultural Sauriana.

Ao se trabalhar a mobilidade da população religiosa brasileira, a migração torna-se uma das principais modalidades nesse processo, pois indica a mudança de residência habitual entre duas unidades geográficas distintas em um período de tempo estabelecido. O Censo Demográfico, nesse caso, é a fonte de dados principal para a análise dos fluxos populacionais no território, apresentando grandes inovações em relação aos censos anteriores de 1980. O Censo de 2010, por exemplo, o quesito do local de última residência no nível municipal (na informação de "última etapa") foi reincorporado, solucionando os problemas encontrados no Censo 2000.

Existem dois quesitos independentes que possibilitaram a mensuração (via técnica direta) em estudos migratórios: "data fixa" e "última etapa". O primeiro quesito indaga sobre o lugar de residência em uma determinada data do passado, normalmente 5 anos antes da data de referência do recenseamento no caso, por exemplo, em $1^{\circ}$ de setembro de 1986, residiam 
em localidade diferente da que residem na data de referência do Censo. Do ponto de vista analítico, este é um dado de fácil interpretação. O migrante será conceituado como aquele que residia em lugares diferentes nas duas datas, enquanto o não-migrante residia no mesmo local.

O quesito "última etapa" indaga àqueles com menos de dez anos de residência no município que indiquem o município e UF, ou país estrangeiro, em que moravam antes de se mudarem para o município de residência na data do Censo. Portanto, foram utilizados os quesitos ora descritos na estruturação dos dados da pesquisa, como será melhor detalhado na metodologia.

No que diz respeito à evolução das migrações, uma extensa literatura trata de diferentes aspectos da dinâmica migratória e da mobilidade (num sentido mais amplo), o que por sua vez foi de fundamental importância para contextualizar os diversos processos referentes à configuração atual da distribuição espacial da população e da rede urbana brasileira, como forma de subsídio à análise da evolução da alocação e da dinâmica observada dos pentecostais no território nacional, especialmente em Minas Gerais, objeto de análise. Assim, autores como MARTINE (1990), SANTOS (1993), FAISSOL (1994), FARIA (1976), CANO (1985) - consultados para a formulação do estudo - e entre outros autores foram utilizados no sentido de contextualizar a dinâmica territorial ocorrida no país, principalmente a partir da década de 1950.

Assim, o levantamento de estudos sobre as migrações internas tem sido fundamental nos processos recentes de redistribuição e desconcentração espacial da população no Brasil contemporâneo, visto que, atuam na redinamização da rede de localidades, difundindo inovações derivadas de grandes áreas urbanas, viabilizando enfim a ocupação de antigos vazios demográficos.

Em relação aos dados censitários de religião, o Censo Demográfico de 1991 registrou as mudanças mais expressivas na composição religiosa da população brasileira. Notadamente, o crescimento do segmento populacional que se declarou evangélico passou de 9,0\% em 1991 para 15,4\% em 2010, destes, 13,3\% são evangélicos pentecostais. Neste período, o segmento católico embora majoritário, deu continuidade à tendência de declínio, passando de $83 \%$ em 1991 para 64,6\% em 2010.

Considerando o período de 2000 a 2010, observou-se, ainda, o aumento expressivo do segmento da população que apenas respondeu ser evangélica, não se declarando, portanto, 
como de missão ${ }^{2}$ ou de origem pentecostal. Confirmou-se a tendência de crescimento do segmento de evangélicos pentecostais, o que ocorreu em todas as Grandes Regiões do País.

O crescimento dos grupos evangélicos pentecostais vem apresentando ao longo das décadas uma nova configuração no cenário religioso, devido em grande parte as mudanças dos padrões migratórios brasileiros.

A relação da migração com a religião nos instiga a entender mais sobre o ritmo demográfico religioso, especialmente o de origem pentecostal, grupo este que vem se destacando cada vez mais no Brasil e em Minas Gerais. No que diz respeito à sua expansão territorial, em termos de participação da parcela da população que tem se tornado adepto a essa religião, o que justifica o estudo da evolução e expansão das migrações, sua configuração espacial e seus principais condicionantes.

\section{MATERIAIS E MÉTODO}

\section{Variável Religião e Migração segundo o IBGE}

Para o referente estudo, as variáveis e indicadores relacionados à religião e migração, foram obtidos através dos dados da Amostra disponibilizados pelo Censo Demográfico de 2010. Em relação às variáveis e indicadores da religião em estudo foi necessária a elaboração de um novo dicionário agregado da religião, para o cruzamento e a análise dos dados, visto a distinção e complexidade do grupo de religiões.

Em relação ao quesito migração, os critérios "data fixa" e "última etapa", que investiga a unidade da federação, município ou país estrangeiro de residência há exatos 5 anos antes da data de referência, e àqueles com menos de dez anos de residência no município que indiquem o município e UF, ou país estrangeiro, em que moravam antes de se mudarem para o município de residência na data do Censo, respectivamente, foram utilizados para esta pesquisa, pois tratam-se de quesitos que permitem a construção de saldos migratórios, taxas líquidas de migração, fluxos migratórios, além de indicadores mais elaborados do ponto de vista demográfico, como a identificação de processos como a remigração, a migração de retorno (inclusive de curto prazo), permitindo um maior detalhamento quanto à análise da expansão dos pentecostais.

\footnotetext{
${ }^{2} \mathrm{Na}$ segunda metade do século XIX, missionários norte-americanos vindos principalmente do sul dos Estados Unidos e por europeus, instalaram no país um segundo momento que irradiou por todo o cenário nacional, denominado de Protestantismo Missionário.
} 
Os dados de migração relacionados referem-se ao período 01 de setembro de 1986, 31 de julho 1995, 31 de julho de 2005 e 31 de julho de 2010. Por exibir o resultado final dos movimentos populacionais entre dois locais em um período de tempo determinado, esse quesito permite o cálculo de saldos migratórios entre essas localidades investigadas. Os saldos migratórios quinquenais, obtidos pela diferença do número de imigrantes e emigrantes, representam o resultado líquido da migração entre tais localidades nos 5 anos anteriores ao Censo.

Em relação ao quesito "data fixa”, Rigotti (1999) afirma que o mesmo possui grandes vantagens por ser um intervalo de tempo menor que o período intercensitário, possuir cálculos e não estimativas; produz dados desagregados para imigrantes e emigrantes e os saldos são calculados para pares de unidades espaciais, e não para uma unidade espacial e o resto do mundo.

\section{O tratamento dos dados religiosos}

Em relação ao grupo religioso proposto para análise, a grande distinção e complexidade do campo "Grupos de Religião", adotado pelo IBGE, exige um agrupamento em uma única categoria denominada de "Evangélicas de origem pentecostal".

Os números da população religiosa foram definidos através da religião professada pela pessoa. Segundo o IBGE, aquela que não professava qualquer religião foi classificada como sem religião. A criança que não tinha condição de prestar a informação foi considerada como tendo a religião da mãe.

Em relação à análise temporal, a utilização dos dados censitários de 1991, 2000 e 2010, uma compatibilização do código da variável 'religião' tornou-se necessária, para adequar o sub-grupo de interesse, devido ao número diferenciado de denominações evangélicas de um Censo para o outro.

O agrupamento e a rodagem dos microdados das denominações evangélicas consideradas de origem pentecostal foram realizados por meio do software estatístico SPSS 18.0. As malhas digitais do Brasil e de Minas Gerais adquiridas no IBGE, cuja extensão do arquivo (shapefile) permitiu a utilização do software ArcGis 10.1, utilizado na elaboração das bases cartográficas. 
Executadas as etapas anteriores, o passo seguinte consistiu na elaboração de mapas coropléticos $^{3}$ (base digital), baseado no agrupamento de casos em intervalos de valores. Para a manipulação dos dados absolutos, de proporção e de taxa de crescimento dos pentecostais em Minas Gerais, o nível de escala municipal foi o mais indicado para a elaboração dos mapas.

A escala municipal, enquanto unidade geográfica de estudo, fornece dados mais detalhados a respeito das informações populacionais, principalmente na prática religiosa exercida pela pessoa.

Desta forma, através do novo dicionário agregado de religião e dos indicadores relacionados às variáveis migratórias, os dados demonstraram informações referentes às características da dinâmica espacial religiosa e sua configuração nos períodos 1991, 2000 e 2010, em relação as mesorregiões mineiras. O mapa 4 demonstra a taxa de crescimento dos pentecostais no período 1991-2000.

Mapa 1: Proporção dos protestantes pentecostais em Minas Gerais: 1991

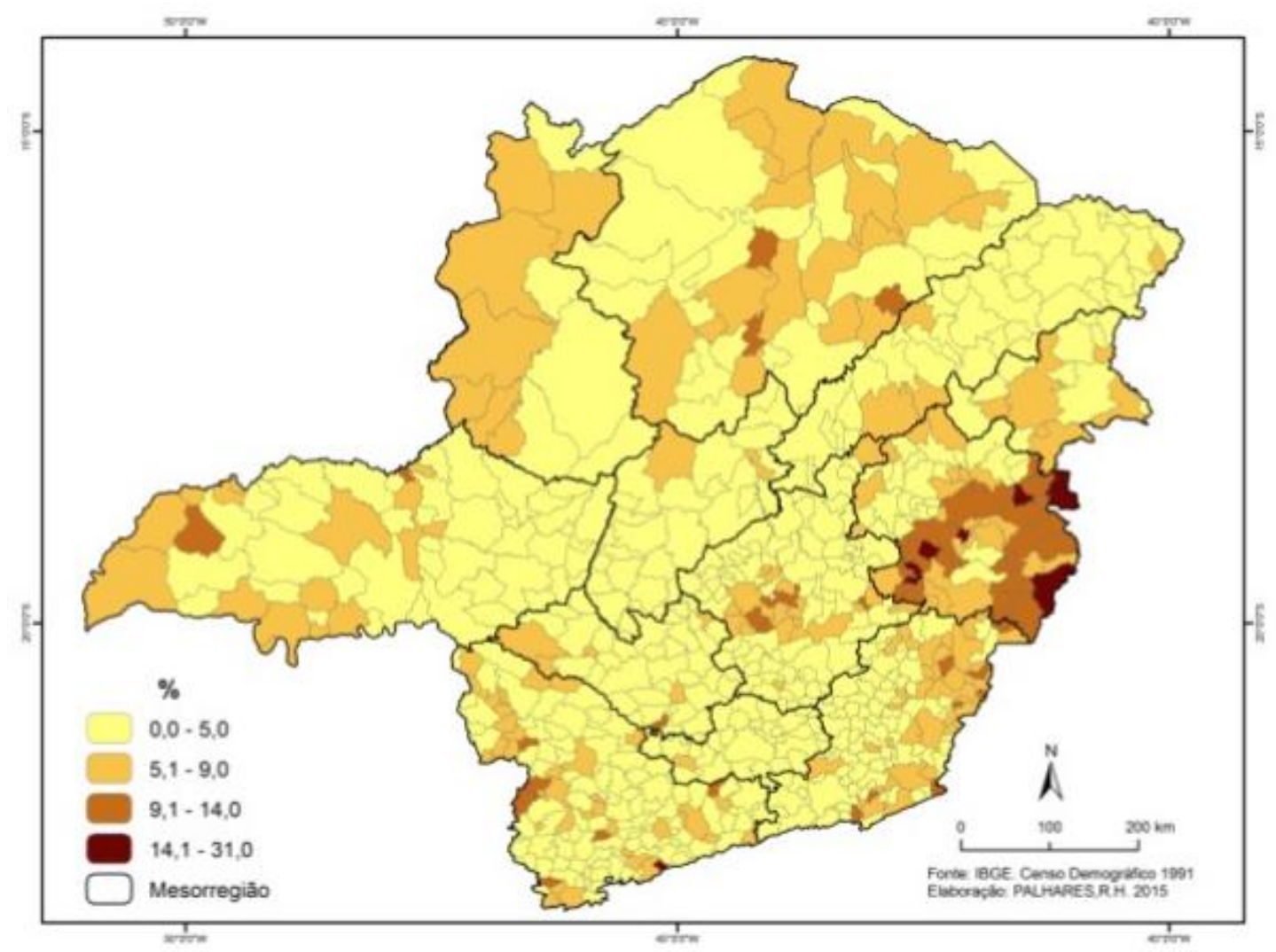

Fonte: IBGE. Censo demográfico 1991

\footnotetext{
${ }^{3}$ Mapa coroplético é uma técnica de produção de mapas. Cada unidade de interesse passa a ser destacada de forma a representar diferentes magnitudes de um determinado atributo, ou seja, proporcionalmente ao nível de medida da variável estatística que está sendo retratada no mapa. (ARCHELLA e THÉRY, 2008).
} 
Mapa 2: Proporção dos protestantes pentecostais em Minas Gerais: 2000

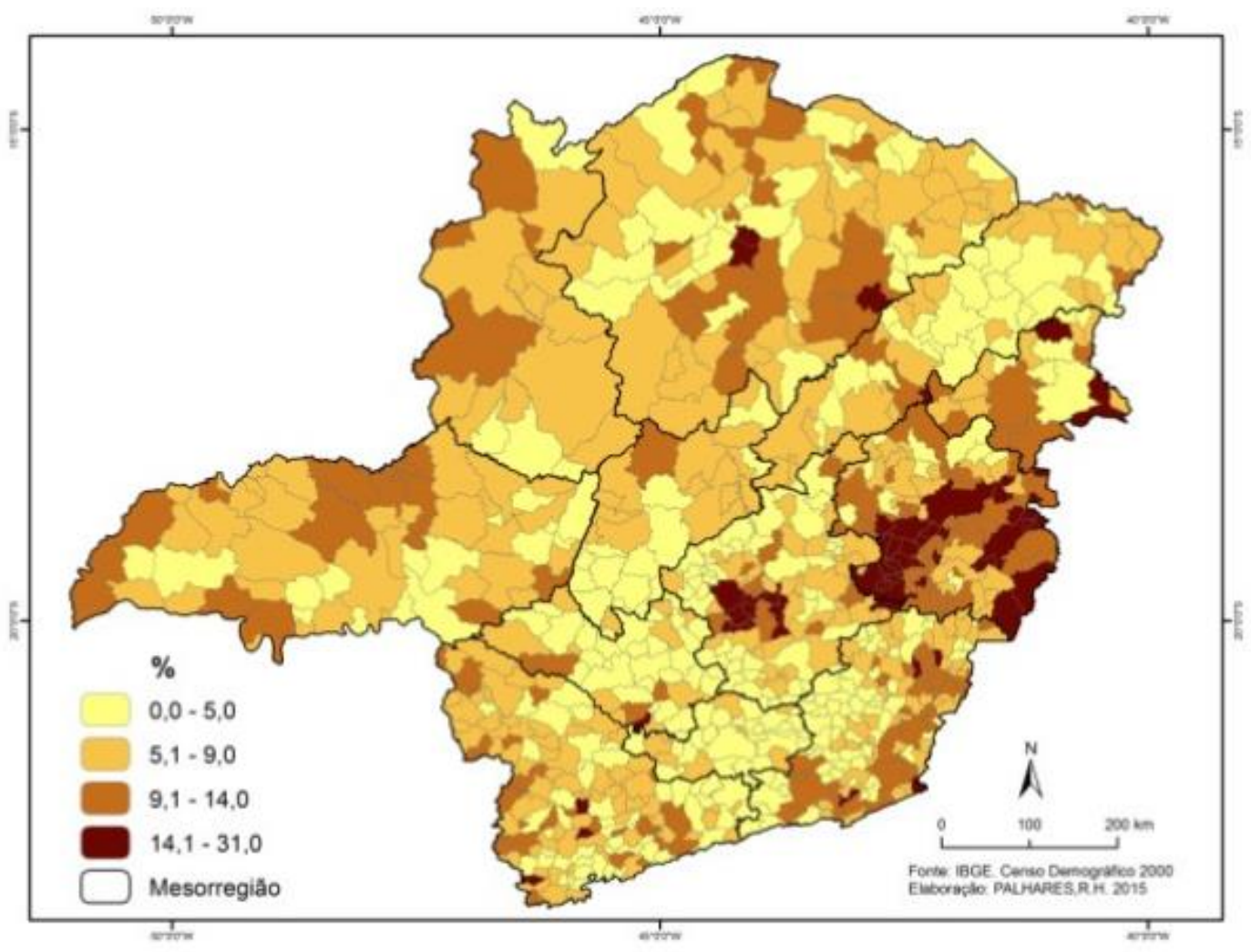

Fonte: IBGE. Censo demográfico 2000

Mapa 3: Proporção dos protestantes pentecostais em Minas Gerais: 2010

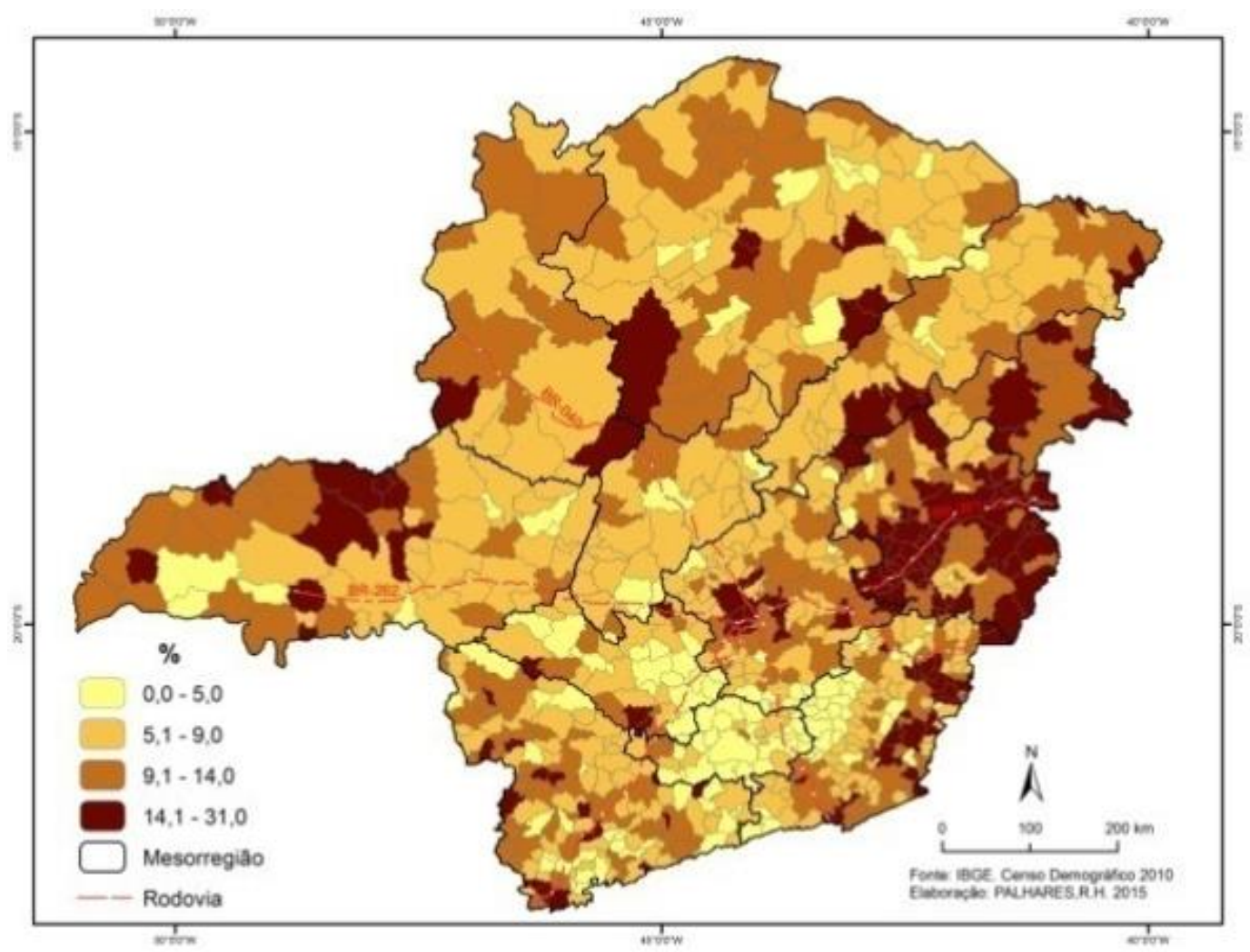

Fonte: IBGE. Censo demográfico 2010 
Mapa 4: Taxa de crescimento dos protestantes pentecostais em Minas Gerais: 1991-2000.

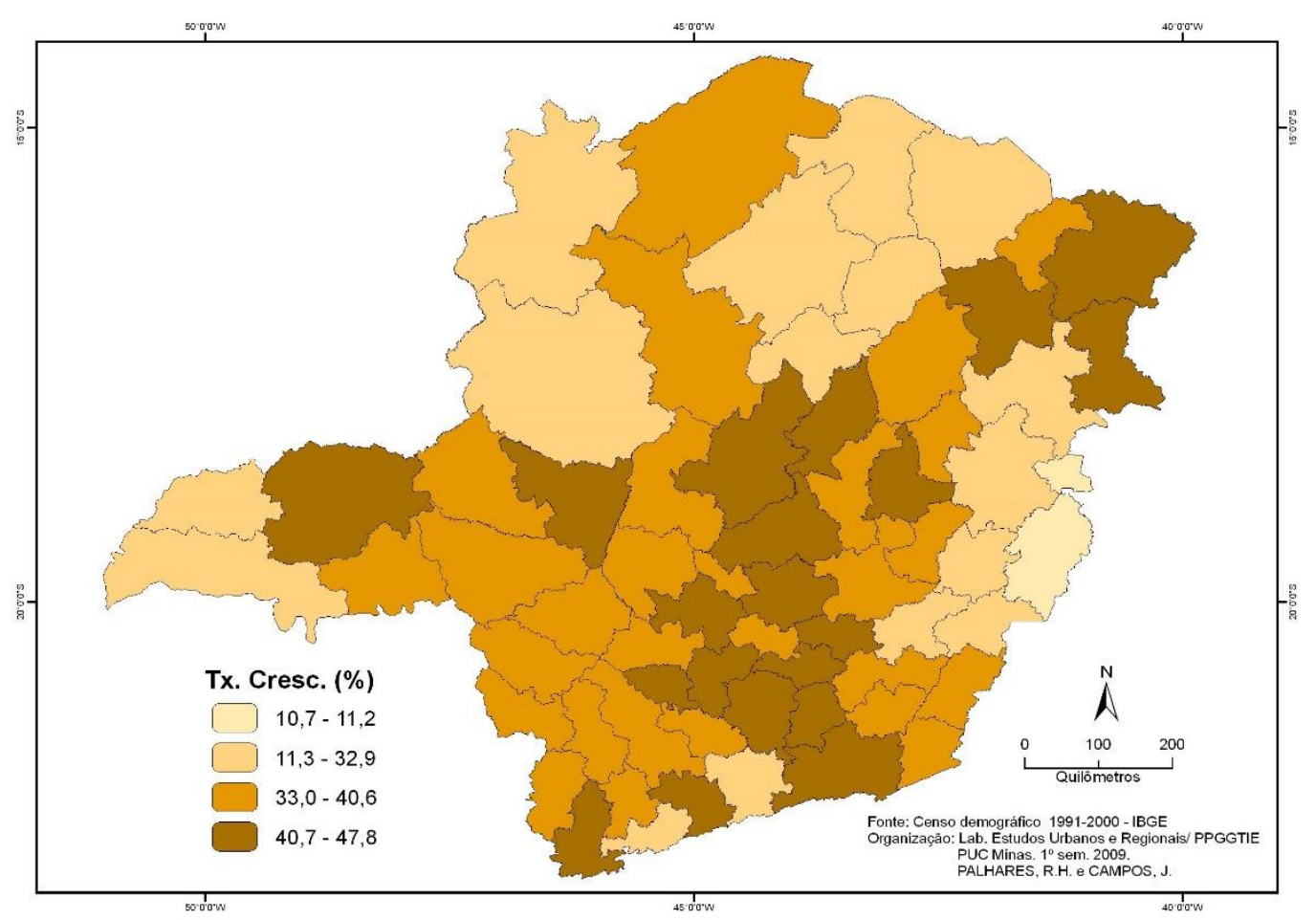

Fonte: IBGE. Censos demográficos 1991 e 2000.

\section{CONSIDERAÇÕES E DISCUSSÕES}

O crescimento da população pentecostal não se faz de modo homogêneo no estado de Minas Gerais. Isto ocorre, porque algumas áreas do Estado apresentam um desenvolvimento mais elevado, o que acaba exercendo um papel considerável na distribuição não só da população total, mas também na população religiosa.

De maneira geral, o mapa demonstra as áreas do estado de Minas Gerais que apresentaram os maiores ganhos populacionais no período de 1991-2000.

Os protestantes pentecostais tiveram como destino as Mesorregiões do Triângulo Mineiro, Zona da Mata, Vale do Rio Doce, Sul/ Sudoeste e Metropolitana de Belo Horizonte. Acrescidas da Mesorregião Norte de Minas, representam mais de $50 \%$ da população protestante no Estado.

Os padrões apresentados respondem ao objetivo geral proposto, fornecendo detalhes importantes sobre o crescimento dos pentecostais em Minas Gerais. O IBGE revela que apesar dos pentecostais predominarem entre os protestantes, $60 \%$ deles não nasceram em famílias pentecostais. Sugere-se que do total de seguidores dessas igrejas, cerca de $45 \%$ foram convertidos a partir do catolicismo e do protestantismo clássico. 
A mudança no cenário religioso brasileiro: o rearranjo espacial do movimento Pentecostal Ricardo Henrique Palhares

\section{REFERÊNCIAS}

ALMEIDA, Ronaldo de. Trânsito Religioso no Brasil. Perspectiva: São Paulo. Vol.15 no 3. jul/set. 2001.

ALMEIDA, Ronaldo de. A expansão pentecostal: circulação e flexibilidade. FFLCH-USP. São Paulo, 2002.

ANTONIAZZI, Alberto. Por que o panorama religioso no Brasil mudou tanto? Revista Horizonte: Belo Horizonte. Vol.3, nº.5, pág. 13-39, $2^{\circ}$ sem. 2004.

CANO, Wilson. Desequilíbrios regionais e concentração industrial no Brasil.1930- 1970. Rio de Janeiro: Global, 1985.

CLAVAL, Paul. Le theme de la religion dans les etudes geographiques. Université de Paris-IV. Géographie et cultures, $n^{\circ} 2,1992$.

COSTA, E. B. Protestantism, modernization and cultural change in Brazil. Berkeley, University of California. Tese de doutorado, 1979. Não publicado.

FAISSOL, S. O espaço, território, sociedade e desenvolvimento brasileiro. In: FUNDAÇÃO INSTITUTO BRASILEIRO DE GEOGRAFIA - IBGE, Rio de Janeiro, 1994.

FARIA, Vilmar. O sistema urbano brasileiro; um resumo das características e tendências recentes. Estudos CEBRAP, São Paulo, n.18, p. 91-115, 1976.

GIL FILHO, Sylvio Fausto. Geografia da religião: reconstruções teóricas sob o idealismo crítico. In: Salete Kozel; Josué da Costa Silva; Sylvio Fausto Gil Filho. (org.). Da percepção e cognição à representação: reconstruções teóricas da Geografia Cultural e Humanista. Edufro: São Paulo. $1^{\text {a }}$ Ed. pág. 207-222. 2007.

IBGE. Instituto Brasileiro de Geografia e Estatística. Censos Demográficos 1991-20002010.

JACOB, C. R.; HEES, D.R.; WANIEZ,P.; BRUSTLEIN, V. Atlas da filiação religiosa e indicadores sociais no Brasil. Editora PUC Rio e Edições Loyola: São Paulo, 240 p. 2003.

NERI, M. A ética católica e o espírito da revolução feminina. Acesso em: 10/06/2008. Disponível em: <http://www.fgv.br/ cps/religioes/Apresenta\%E7\%E3o/valor.pdf> .

RATTS. A.J. Gênero, raça e espaço: trajetórias de mulheres negras. Comunicação apresentada no XX Encontro Nacional da ANPOCS, Caxambu-MG, out. 2003.

RIGOTTI, J. I. R. Técnicas de mensuração das migrações, a partir de dados censitários: Aplicação aos casos de Minas Gerais e São Paulo. 1999. Tese (Doutorado em Demografia). CEDEPLAR/UFMG. Belo Horizonte, 1999.

ROSENDAHL Zeny. Geografia da Religião: uma Proposição Temática. Espaço e Cultura, UERJ, n 1 , out/ 1995. 
A mudança no cenário religioso brasileiro: o rearranjo espacial do movimento Pentecostal

Ricardo Henrique Palhares

ROSENDAHL, Zeny. Território e Territorialidade: Uma perspectiva geográfica para o estudo da religião. In: ROSENDAHL, Zeny e CORREAA, Roberto Lobato. (org). Geografia: Temas sobre Cultura e Espaço. Editora UERJ: Rio de Janeiro, pág. 191-226, 2005. 